\title{
Evaluation of the compactness of subbase and base geomaterials by using stiffness
}

\author{
BABAK KAZEMI DARABADI $^{1, *^{*}}$, ALIREZA KHAVANDI KHIAVI ${ }^{2}$, AHAD OURIA $^{3}$ and \\ RAMIN RASOULI'D
}

${ }^{1}$ Department of Civil Engineering, Moghadas Ardabili Institute of Higher Education, Ardabil, Iran

${ }^{2}$ Department of Civil Engineering, University of Zanjan, Zanjan, Iran

${ }^{3}$ Civil Engineering Department, University of Mohaghegh Ardabili, Ardabil, Iran

e-mail: babak.msi@gmail.com; Khavandi@znu.ac.ir; aouria@uma.ac.ir; rasouli.ramin@znu.ac.ir

MS received 9 November 2017; revised 24 May 2018; accepted 5 June 2018; published online 30 October 2018

\begin{abstract}
Stiffness of soil that is defined as ratio of load to deflection depends on some physical properties such as compactness and water content. The purpose of this research study is to use stiffness for estimating compactness of granular geomaterials that are used as subbase and base courses of roads. In this research study, the stiffness of soil samples was determined according ASTM D6758-08 test method by using electro-mechanical device. The dry density of the compacted soil was determined by sand-cone method in the field. More than 80 laboratory and in situ tests were performed. The obtained stiffness data was used to establish a relationship between stiffness, compaction ratio and water content. The results showed that there is a strong relationship between the stiffness, compaction ratio and water content. Also, the result of validation showed that there is good correlation between in situ and laboratory tests results.
\end{abstract}

Keywords. Compaction ratio; soil stiffness; water content; subbase materials; base materials.

\section{Introduction}

Compaction is a method of decreasing soil porosity and void ratio and increasing its density by applying energy to the soil. Compaction can improve some engineering properties of soils such as bearing capacity and can decrease swelling and subsidence potential. Therefore, compaction control has become one of the most important measures of quality controlling of earth embankments, structural backfills, dams, road fills and pavement courses. In most of the projects, the compaction ratio of soils is determined by measuring the in situ dry density of soil and comparing it with a reference value called laboratory maximum dry density. Laboratory maximum dry density for a specific soil is the maximum dry density that can be achieved by applying a specific compaction effort in the laboratory (for example modified Proctor test method). Measuring compaction ratio by this method is usually time-consuming and has some limitations. For example, this method is not suitable for saturated soils, or highly plastic soils that would deform or compress during the excavation of the test hole, and also this method may not be suitable for soils consisting of unbound granular materials that will not maintain stable sides in the test hole [1].

*For correspondence
Rapid and accurate estimating of soil compaction during construction can prevent applying excessive compaction energy to the soil and can also reduce the risk of insufficient compaction and its consequent problems.

Some non-destructive test methods such as using nuclear gauge and electromagnetic methods have been developed for rapid measurement of dry density and compaction ratio, but each of these methods have some advantages and disadvantages. Although nuclear methods are inexpensive, highly reliable and accurate methods of measuring density, they have some disadvantages such as limitations in handling, storage, and transportation of radioactive materials [2].

Stiffness is an indicator of soil strength against deflection that can be defined as the ratio of applied force to the resulted deflection as follows:

$$
k=\frac{P}{\delta}
$$

Where $\mathrm{P}$ is applied force and $\delta$ is the resulted deflection.

Stiffness is affected by layer thickness, boundary conditions, the support offered by underlying layers and physical properties of the soil such as grading, porosity, and compactness. In fact, compactness is one of the most important parameters that affect soil stiffness. Also stiffness 
can be used as an important factor for design and quality control of highway pavements.

The structure of soils may be assumed as a series of springs that stiffness of these springs is the ratio of applied force to the resulted deflection. Any applied stress to the soil causes deflection. The wheel load applies repetitive pressure to the pavement surface and this pressure transmits to the base, subbase and subgrade. Although the pavement layers are constructed separately, they work as a system and are dependent on each other intensively to have uniform and en bloc performance. If the stiffness of layers is proportional, the deflection of layers will also be proportional and pavement will perform better against the applied load. Besides, in order to confine deflection of pavement layers, their stiffness must be greater than a specific value. On the other hand, evaluation of soil compaction ratio by using some rapid methods such as using stiffness measured by ASTM D6758-08 can help appropriate quality control. Through an understanding of how stiffness relates to density for a particular material, the stiffness achieved can be related to percent compaction in connection with density based compaction control [3]. Wu et al found that the soil stiffness gauge (SSG) has great potential for use as an alternative quality control device in pavement construction. Furthermore, a linear correlation model was developed between stiffness measured by SSG and the modulus measured with other techniques like portable seismic pavement analyzer (PSPA), the falling weight deflectometer (FWD), etc. [4]. Also, it was found that the SSG modulus is higher than that from resilient modulus test typically used for pavement design [5].

The purpose of this research is to establish a relationship among stiffness, compaction ratio and water content of granular soils that are used for pavement construction. Generally, there is a clear correlation present between the rise in moisture and a subsequent decrease in materials stiffness [6]. Some researchers have investigated about such a relation. One of them believes that estimating dry density from measured stiffness and moisture content is possible based on following relationship which is a minor modification of the work conducted by Hryciw and Thomann [7, 8]:

$$
\rho_{d}=\frac{\rho_{0}}{1+1.2\left[\frac{C . m}{K}-0.3\right]^{0.5}} .
$$

Where $\rho_{d}$ is dry density, $\rho_{0}$ is ideal zero void density, $\mathrm{m}$ is moisture content, $\mathrm{K}$ is stiffness and $\mathrm{C}$ value needs to be defined for a geographical region or group of soil classes from companion measurements of stiffness, moisture content and dry density to be fitted to a linear equation with two independent variables, $\mathrm{K}$ and $\mathrm{m}$ as Eq. (3).

$$
C=n\left(\frac{K}{m^{0.25}}\right)+b
$$

Where $\mathrm{n}$ is the slope of line and $\mathrm{b}$ is the intercept.
Chen et al investigated the relation between the soil stiffness and dry density determined by the nuclear gauge. Their results showed that stiffness increases with increasing dry density, but based on their results the relationship between stiffness and dry density was very poor [9]. In other study, Ellis et al could not find such a strong relationship [10]. Fiedler found a poor relation between dry density and stiffness [11]. Ooi and $\mathrm{Pu}$ found that stiffness of fine grained cohesive soils was affected by moisture content that was used for compaction of the soil. Based on their results, stiffness increases with increasing the moisture content that was used for compaction of the soil to a peak point and then decreases, but the peak of stiffness occurs at moisture content less than the optimum moisture content of compaction. They also showed that for cohesive soils there is no direct relationships between stiffness and dry density and a stiffness value can be corresponded to several dry density values depending on the moisture content of the soil [12]. The results of Lenke et al uphold this fact [13]. Akbulut et al conducted standard proctor tests on cohesive soils to determine their optimum water content and maximum dry unit weight relationship. The results show that addition of cationic and anionic surfactants to cohesive soils decreased the maximum dry densities [14].

Han and Vanapalli introduce a methodology to predict the non-linear stiffness-suction relationship for unsaturated soils. The stiffness properties at saturation and unsaturated condition and soil-water characteristic curve (SWCC) were used for prediction. Reasonable prediction of the stiffnesssuction was provided for all the studied soils [15].

Edil and Benson by measuring soils specification at 13 construction sites around the state of Wisconsin; found a relationship with stiffness, dry unit weight and water content for different kind of soils. Based on their study, the dependency of stiffness on dry unit weight and water content was obscured, but individual material follows a pattern which is consistent with other researches [16]. Most of these researches have been conducted at a limited compaction ratio range (mostly in high compaction levels). Since the stiffness value is less sensitive to density or compaction ratio at high compaction levels, they could not establish a strong relationship. In this research study, we have tried to collect data over a wide range of compaction levels. So we were able to study variations of stiffness regarding density, compaction ratio and water content more accurately.

\section{Experimental plan}

In this research study, on two types of granular cohesionless soils, a series of dry density and water content measurements along with stiffness determination by electro-mechanical device were conducted in the field and laboratory. The tested base material was classified as GP-GM in unified 
Table 1. Materials properties.

\begin{tabular}{|c|c|c|c|c|c|c|c|c|}
\hline \multirow[b]{2}{*}{ Materials } & \multicolumn{2}{|c|}{ Classification } & \multirow{2}{*}{$\begin{array}{l}\text { Coefficient of } \\
\text { Uniformity } C_{u}\end{array}$} & \multirow{2}{*}{$\begin{array}{l}\text { Coefficient of } \\
\text { Curvature } C_{c}\end{array}$} & \multirow{2}{*}{$\begin{array}{l}\text { Plasticity } \\
\text { Index }\end{array}$} & \multirow{2}{*}{$\begin{array}{l}\text { Maximum dry } \\
\text { density }\left(\mathrm{g} / \mathrm{cm}^{3}\right)\end{array}$} & \multirow{2}{*}{$\begin{array}{c}\text { Optimum } \\
\text { moisture content } \\
(\%)\end{array}$} & \multirow{2}{*}{$\begin{array}{l}\text { Minimum dry } \\
\text { density }\left(\mathrm{g} / \mathrm{cm}^{3}\right)\end{array}$} \\
\hline & USCS & AASHTO & & & & & & \\
\hline $\begin{array}{l}\text { Base } \\
\quad \text { Material }\end{array}$ & $\begin{array}{l}\text { GP- } \\
\text { GM }\end{array}$ & A-1-a & 22 & 3.2 & N.P. & 2.20 & 5 & 1.22 \\
\hline $\begin{array}{l}\text { Subbase } \\
\text { Material }\end{array}$ & $\begin{array}{r}\text { GW- } \\
\text { GM }\end{array}$ & A-1-a & 65 & 1.3 & N.P. & 2.10 & 7 & 1.24 \\
\hline
\end{tabular}

soil classification system and A-1-a on AASHTO soil classification system and the subbase material was GW-GM and A-1a based on unified soil classification system and AASHTO soil classification system, respectively. Table 1 shows the properties of the materials. The particle size distributions of two materials are shown in figure 1.

The in situ dry density and the maximum dry density of the soils were measured according to ASTM D1556 (12) and ASTM D1557 (1) test methods, respectively and the compaction ratio was determined as follows:

$$
R c=\frac{\gamma_{d}}{\gamma_{d \max }}
$$

Where $\gamma_{d}$ is in situ dry density and $\gamma_{d \max }$ is maximum dry density achieved based on modified proctor compaction energy.

Electro-mechanical method according to ASTM D6758 was used to determine soil stiffness [3]. In this method, the apparatus imparts very small dynamic forces to the soil at 25 steady state frequencies between 100 and $196 \mathrm{~Hz}$ that can cause very small deflections (less than $1.27 \times 10^{-6} \mathrm{~m}$ ). The resulted deflections are measured and stiffness is calculated at each frequency. The average stiffness value is displayed by the apparatus as the soil stiffness [3].

At the field, stiffness of soil was measured at a specified spot and then a test hole was dug exactly at the same place and the dry density of soil was measured based on ASTM D1556 test method [17] as in situ tests. Since dry density measurement by sand-cone device is possible only for sufficiently compacted soils that are firm enough to withstand the pressure exerted in digging the hole without sloughing and sliding, thus it was not possible to obtain any dry density data at low compaction levels. Therefore, a wooden box was prepared and the soils were compacted inside it at different compaction levels by using a dropping weight. The soils were compacted at optimum moisture content.

The stiffness of the compacted soil in the box was measured by electro-mechanical device according to ASTM D6758 and the density of the soil was also determined by using the volume of the box and the weight of the compacted soil inside the box. In order to reduce the effect of boundary conditions, we had to choose proper dimensions for the box. The depth of the box was chosen $30 \mathrm{~cm}$ because the measurement depth of the apparatus was 22 to

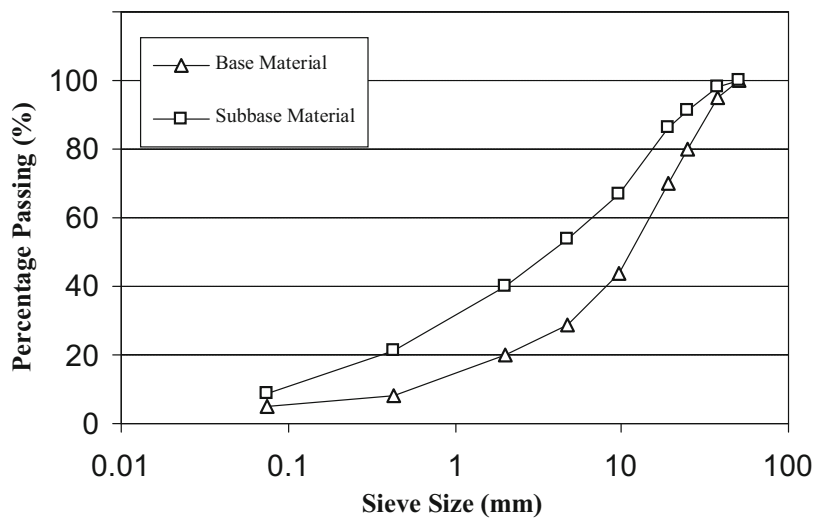

Figure 1. The gradation of the tested materials.

$31 \mathrm{~cm}$ from the surface according to the manufacturer's manual [18]. In addition, Abu-Farsakh et al have investigated the influence depth of apparatus and have suggested a 19 to $20 \mathrm{~cm}$ depth [19]. Lenke et al in a similar research have investigated the effect of boundary conditions by testing granular dry uniform-sized sand in a steel box with $76 \mathrm{~cm}$ length, $71 \mathrm{~cm}$ width and $61 \mathrm{~cm}$ depth. Their observations demonstrated that the apparatus response is attenuated for measurements close to the lateral boundary. Stiffness measurements are stabilized at a lateral distance from the vertical boundary on the order of 8 to 10 inches. They also found that the apparatus provides meaningful stiffness results when the distance to horizontal boundaries are on the order of 12 inches deep and the distance to any lateral boundaries is on the order of 9 inches. These numbers are consistent with the apparatus manufacturer's claims regarding the minimum layer thickness that may be evaluated and the proximity of buried objects [13]. Thus in this research, a box with $80 \times 80 \times 30 \mathrm{~cm}$ dimensions (figure 2) was used and all the stiffness measurements were conducted at the center of the box.

\section{Results analysis and discussion}

The obtained data contain the results of measurements in the field and laboratory. The water content of the majority of tested material was $\pm 2 \%$ about the optimum moisture content. The data were plotted on coordinate axis so that the 


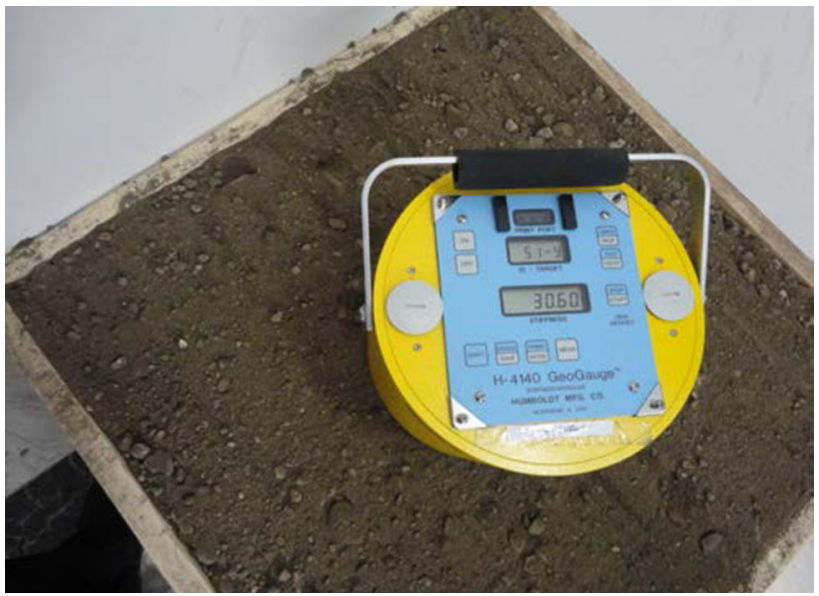

Figure 2. Stiffness measurement using electro-mechanical device at the laboratory.

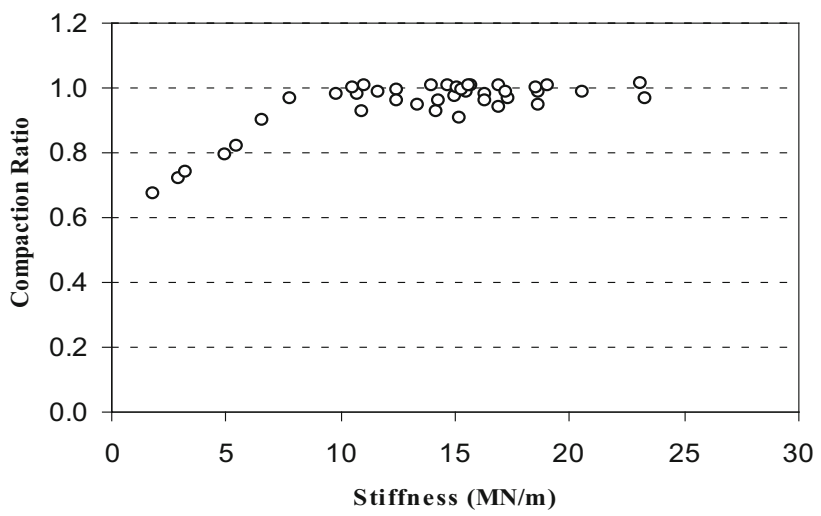

Figure 3. Stiffness versus compaction ratio for base material.

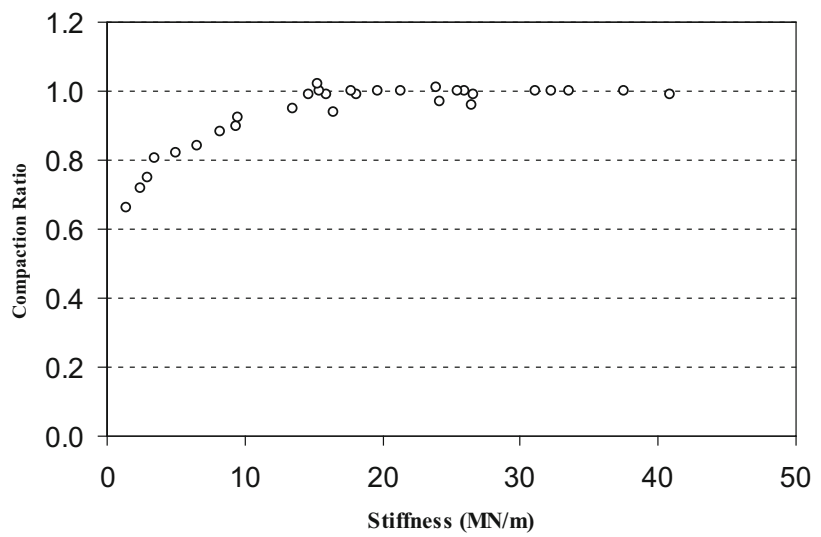

Figure 4. Stiffness versus compaction ratio for subbase material.

horizontal axis indicated stiffness and the vertical axis indicated $\frac{\gamma_{d}}{\gamma_{\text {dmax }}}$ or compaction ratio (figures 3 and 4). The trend of data showed that at the first stages when soil was insufficiently compacted; stiffness increases slightly due to compaction. When compaction achieves a specific value, rate of compaction ratio toward stiffness scales down and

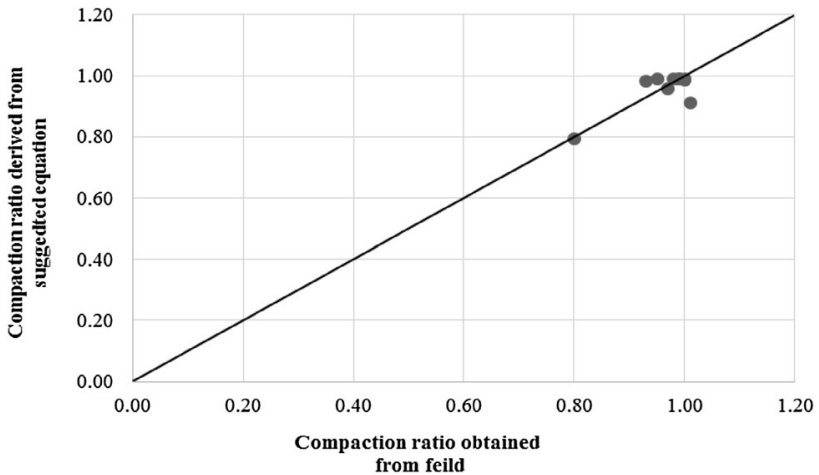

Figure 5. Compaction ratio values resulted from Eq. (5) in regard to directly measured values for base material.

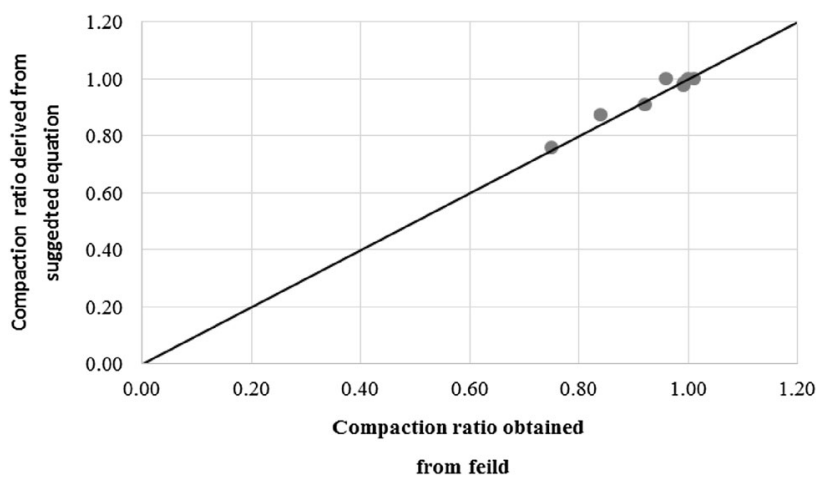

Figure 6. Compaction ratio values resulted from Eq. (5) with regard to directly measured values for subbase material.

tends to a constant value. In fact, this value is the maximum measure of compaction for a specific compaction energy.

In practice, the compacted soil behavior is characterized by the pair of variables $\left(\gamma_{d}, \omega\right)$. As shown in figures 3 and 4 , dry of optimum compaction leads to more rigid soils [20], which have higher stiffness.

Based on figures 3 and 4, at high compaction levels (compaction levels near 100\%), there are different stiffness values. This implies that in addition to compaction, other parameters such as water content, aggregate gradation, particle arrangement, etc. affect stiffness [15]; but from the view of compaction, it is possible to specify a minimum value of stiffness for each soil type that can warrant the sufficient compaction.

In order to achieve the objects of the research study, 80 measurements at the field and laboratory were done and $25 \%$ of data were discarded for validation. By conducting statistical analysis it was identified that the Eq. (5) can be best fitted to the base and subbase materials data.

$$
R_{c}=\frac{A}{1.34+0.771^{\left(S-\frac{89.7}{\omega^{\omega}}\right)}}
$$

Where $R_{c}$ is the compaction ratio, $\mathrm{S}$ is the stiffness [MN/ $\mathrm{m}], \omega$ is water content and $\mathrm{A}$ is a constant coefficient. The aim was to calibrating the equation and determining suitable values for the coefficient. For this reason trial and error 
Table 2. Kolmogorov-Smirnov tests result.

\begin{tabular}{|c|c|c|c|c|c|c|c|c|}
\hline \multirow[b]{2}{*}{ Materials } & & \multicolumn{2}{|c|}{ Normal Parameters } & \multicolumn{3}{|c|}{ Most Extreme Differences } & \multirow[b]{2}{*}{ Test Statistic } & \multirow[b]{2}{*}{ Asymp. Sig.(2-tailed } \\
\hline & & Mean & Std. Deviation & Absolute & Positive & Negative & & \\
\hline \multirow[t]{2}{*}{ Base } & Laboratory test value & 0.9440 & 0.08818 & 0.272 & 0.227 & -0.272 & 0.272 & 0.000 \\
\hline & Model predicted value & 0.9487 & 0.08407 & 0.300 & 0.237 & -0.360 & 0.300 & 0.000 \\
\hline \multirow[t]{2}{*}{ Subbase } & Laboratory test value & 0.9377 & 0.10076 & 0.289 & 0.223 & -0.289 & 0.289 & 0.000 \\
\hline & Model predicted value & 0.9282 & 0.09878 & 0.354 & 0.266 & -0.354 & 0.354 & 0.000 \\
\hline
\end{tabular}

Table 3. Spearman tests result.

\begin{tabular}{lcc}
\hline & \multicolumn{2}{c}{ Spearman's rho } \\
\cline { 2 - 3 } Materials & Correlation coefficient & Sig. (2-tailed) \\
\hline Base & 0.518 & 0.003 \\
Subbase & 0.719 & 0.000 \\
\hline
\end{tabular}

method was used to find best values for coefficients. At the first trial, it is recommended that use $\frac{\gamma_{\text {dmax }}}{\gamma_{\text {dmin }}}$ ratio for coefficient A. The ratio was 1.35 for base material and 1.32 for subbase material.

\section{Validation}

In order to estimate the accuracy and reliability of suggested equation in this research study, the compaction ratio values for $25 \%$ of discarded data first derived from the Eq. (5), for base and subbase, and then were compared with the directly measured compaction ratio values. Figures 5 and 6 show the results. The results show a strong relationship between evaluated and measured compaction ratio values.

Although the model accuracy validated by cross validation method which is shown in figures 5 and 6 for base and subbase materials, respectively; but for more investigation of suggested equation in this research study, statistical tests were done. In order to choose proper statistical test, first data distribution type should be specified. KolmogorovSmirnov (K-S) test was done to determine distribution type of the data. The results of K-S test were shown in table 2 . As the results show, distribution type was not normal. Based on Kolmogorov-Smirnov tests results, Spearman test was selected for model investigation. The results of Spearman tests verified the sufficiency of the correlated equation at the 0.01 level (table 3 ).

\section{Conclusions}

In order to establish a relationship between compaction ratio, stiffness, and water content of subbase and base geomaterials, a series of laboratory and in situ tests were conducted. The obtained data were the results of more than 80 measurements. After analyzing data it was identified that an equation presented was the best fitted to data.

The derived models obviously showed that compaction ratio of tested soils are directly related to their stiffness and water content. The rate of increasing compaction ratio versus stiffness is intense at low compaction levels and after more compaction, it scales down and tends to a constant value that actually this value is ultimate level of compaction ratio due to a specific compaction energy.

\section{Acknowledgements}

The authors would like thank the Technical and Soil Mechanics Laboratory Co. (TSML) for their support. However, the results and opinions presented in this paper do not necessarily reflect the view and policy the company.

$\begin{array}{ll}\text { List of symbols } \\ \mathrm{A} & \text { constant coefficient } \\ \mathrm{b} & \text { intercept } \\ \mathrm{c} & \text { fitted value } \\ \mathrm{K} & \text { stiffness } \\ \mathrm{m} & \text { moisture content } \\ \mathrm{n} & \text { slope of line } \\ \mathrm{P} & \text { force } \\ \mathrm{R}_{\mathrm{c}} & \text { compaction ratio } \\ \mathrm{S} & \text { stiffness } \\ \gamma_{\mathrm{d}} & \text { in situ dry density } \\ \gamma_{\mathrm{dmax}} & \text { maximum dry density } \\ \delta & \text { deflection } \\ \rho_{0} & \text { ideal zero void density } \\ \rho_{\mathrm{d}} & \text { dry density } \\ \omega & \text { water content }\end{array}$

\section{References}

[1] ASTM D1557-02 2002 Standard Test Methods for Laboratory Compaction Characteristics of Soil Using Modified Effort $\left(56,000 \mathrm{ft}-\mathrm{lbf} / \mathrm{ft} 3\left(2,700 \mathrm{kN}-\mathrm{m} / \mathrm{m}^{3}\right)\right)$. American Society of Testing and Materials. Annual Book of ASTM Standards

[2] Allen D L, Schultz Jr D B and Willett D A 2003 Evaluation of Non-Nuclear Density Gauges. Kentucky Transportation 
Centre. Research Report KTC-03-24/FR115-01-1F. University of Kentucky

[3] ASTM D6758-08 2008 Standard Test Method for Measuring Stiffness and Apparent Modulus of Soil and Soil-Aggregate In-Place by Electro-Mechanical Method. American Society of Testing and Materials. Annual Book of ASTM Standards

[4] Wu W, Arellano M, Chen D, Bilyeu J and He R 1998 Using a Stiffness Gauge as an Alternative Quality Control Device in Pavement Construction. Texas Department of Transportation

[5] Sawangsuriya A, Edil T B and Bossche P J 2003 Relationship between Soil Stiffness Gauge Modulus and Other Test Moduli for Granular Soils. J. Transport. Res. Board 1849

[6] Kodippily S, Tighe S L, Henning T F P and Yeaman J 2016 Evaluating Pavement Performance Through Smart Monitoring- Effects of Soil Moisture, Temperature and Traffic. Road Mater. Pavement Design 19

[7] Humbolt Mfg Co 1999 Report Estimation Dry Density from Soil Stiffness and Moisture Content. Norridge

[8] Hryciw R D and Thomann T G 1993 Stress-History-Based Model for Cohesionless Soils. J. Geotechnical Eng. 119

[9] Chen D H, Wu W, He R, Bilyen J and Arrelano M 1999 Evaluation of In-Situ Resilient Modulus Testing Techniques. Texas DOTD Report. Austin.

[10] Ellis R, Bloomquist D, Patel M and Velcu B 2001 Development of Compaction Quality Control Guidelines that Account for Variability in Pavement Embankments in Florida. Transport. Res. Board.

[11] Fiedler S A, Main M and DiMillio A F 2000 In-place stiffness and modulus measurements. In: ASCE Specialty Conf.
Performance Confirmation of Constructed Geotechnical Facilities, pp. 365-376

[12] Ooi $\mathrm{P}$ and $\mathrm{Pu} \mathrm{J} 2003$ Use of stiffness for evaluating compactness of pavement geomaterials. J. Transport. Res. Board 1849: 11-19

[13] Lenke L R, McKeen R and Grush M 2003 Laboratory evaluation of Geogauge for compaction control. J. Transport. Res. Board 1849: 20-30

[14] Akbulut S, Kurt Z, Arasan S and Pekdemir Y 2013 Geotechnical Properties of Some Organoclay. Sädhanā 38: 317-329

[15] Han Z and Vanapalli 2016 Stiffness and Shear Strength of Unsaturated Soils in Relation to Soil-Water Characteristic Curve. Géotechnique. 66

[16] Edil T B and Benson C H 2005 Investigation of the DCP and SSG as Alternative Methods to Determine Subgrade Stability. Wisconsin Highway Res. Prog.

[17] ASTM D1556-00 2008 Standard Test Method for Density and Unit Weight of Soil in Place by the Sand-Cone Method. American Society of Testing and Materials, Annual Book of ASTM Standards.

[18] Humboldt Mfg Co 2002 GeoGuage ${ }^{T M}$ User Guide: Version 4.5. Norridge

[19] Abu-Farsakh MY, Alshibli K, Nazzal M and Seyman E 2004 Assessment of in-situ test technology for construction control of base courses and embankments. Louisiana. Louisiana Transport. Res. Centre LTRC Pro. No. 02-1GT State Pro. No. 736-02-0995

[20] Alonso E E and Pinyol N M 2008 Unsaturated Soil Mechanics in Earth and Rock fill Dam Engineering. In: Proceeding of the $1^{\text {St }}$ European Conference. Durham, United Kingdom 